\title{
NARRATIVAS (MITO)POIÉTICAS DE UMA PROFESSORA SOBRE A EDUCAÇÃO, A CORPOREIDADE E O LAZER EM DIÁLOGOS COM PAULO FREIRE
}

\author{
A TEACHER'S (MYTH)POETIC NARRATIVES ABOUT EDUCATION, \\ CORPOREALITY AND LEISURE IN DIALOGUES WITH PAULO FREIRE
}

\author{
Vânia Noronha - PUC MINAS
}

\section{Resumo}

Tendo como referência a minha história de vida no processo de me tornar professora e a experiência docente ao longo dos quase quarenta anos no ensino básico e no superior, apresento neste artigo narrativas (mito)poiéticas que permitiram analisar a presença dos conceitos de corporeidade e lazer em diálogo com os escritos de Paulo Freire. Desenvolvo o artigo apresentando a aproximação com o pensamento freireano destacando a minha graduação em Educação Física realizada nos tempos da ditadura e algumas experiências ao longo da prática pedagógica nas escolas. Em seguida, extraio dos escritos de Freire elementos para a compreensão sobre o conceito de corpo. Assumindo que o corpo consciente é aquele que vive plena e ludicamente sua presença no mundo, ocupando espaços, experimentando sua cultura, constituindo identidades e subjetividades diversas, relacionando-se consigo, com o outro e com o planeta, discuto o lazer, fenômeno cultural em que essas experiências se tornam possíveis. É nessa dimensão da vida humana que, privilegiadamente, homens e mulheres vivem seus corpos, suas resistências e seus sonhos. Concluo afirmando que o amor, como imaginava Freire, é a saída para nossos sonhos utópicos de construir uma sociedade que proporcione dignidade coletiva, esperança e justiça nesse mundo.

Palavras-chave: Docência, Corporeidade, Lazer, Paulo Freire, Narrativas (mito)poiéticas

\footnotetext{
Abstract

Taking as a reference my life story in the process of becoming a teacher and, over the nearly forty years of teaching in basic and higher education, I point out in this paper (myth)poietic narratives that allowed us to analyse the presence of the concepts of
} 
corporeality and playfulness in my education background and teaching performance as well, in dialogue with Paulo Freire's writings. I develop this article showing my approach to Freire's thought, highlighting my graduation in Physical Education carried out in the times of the dictatorship and some experiences during my pedagogical practice in schools. Then, I bring out elements from Freire's writings for understanding the concept of the body. Assuming that the conscious body is one that fully and playfully lives its presence in the world, occupying spaces, experiencing its culture, constituting different identities and subjectivities, relating to itself, to the other and to the planet, I discuss leisure, a cultural phenomenon wherein these experiences become possible. It is in this dimension of human life that men and women preferentially live their bodies, resistances and dreams. I conclude by stating that love, as Freire imagined, is the way out of our utopian dreams of a society that provides collective dignity and hope for justice in this world.

Keywords: Teaching, Corporeality, Playfulness, Paulo Freire, Narratives (myth)poietic.

\section{Introdução}

"Se muito vale o já feito, mais vale o que será. E o que foi feito é preciso conhecer para melhor prosseguir"

(Fernando Brant e Milton Nascimento)

A experiência corporal é, segundo Keleman (2001), a chave para a busca do sentido da vida, pois é sabido que nós, seres humanos, temos a consciência de que somos finitos e, um dia, nossa carne perecerá. Por isso, vivemos a angústia do tempo que passa e da morte que se aproxima (DURAND, 2002), ocupando nossos dias com diferentes experiências familiares, amorosas, educativas, laborais, lúdicas, espirituais, políticas, dentre tantas outras. Tudo isso se dá no e pelo corpo. MerleauPonty (1999), diz que nossa existência só é possível porque somos e temos um corpo. Antes de existir em pensamento somos um corpo. Muito antes de tomarmos consciência de que éramos um corpo ele já existia no imaginário.

É essa compreensão que faz Keleman (2001) afirmar que também o corpo é assunto da mitodologia, pois o que eles dizem e o funcionamento de seus órgãos e sistemas são frutos da imaginação, estão enraizados em energias, em conflitos e em sua harmonização. Para esse autor, o corpo é dado e o mito, tendo-o como referência, também o é. Assim, a mitologia 
é a poética do corpo cantando a nossa verdade celular. O mito é um poema sobre a experiência de ser corporificado e a nossa jornada somática. É a canção, a criação, a experiência genética que organizou um jeito de cantar, dançar, pintar, contar histórias, que transmitem esta experiência aos outros. (KELEMAN, 2001, p. 17)

Ao longo de nossas vidas experimentamos diferentes corporeidades e essas nos constituem. São essas diferentes experiências corporais que nos permitem escrever histórias e contá-las. Keleman (2001) destaca que o "contar histórias sintetiza e organiza os elementos da experiência numa forma corporal, que nos dá uma configuração pessoal, uma direção e, até mesmo, um senso de significado para estas vivências" (KELEMAN, 2001, p. 99). Essa história que inventamos e contamos a nós mesmos é a do nosso próprio processo de constituição da anima, para Hillman (1984) e do self, para Jung (2002). É ainda uma expressão direta das experiências e dos processos de corporificação (KELEMAN, 2001), estejamos conscientes disso ou não, e, ao contarmos as nossas histórias, é o nosso próprio percurso que está em evidência. A esse movimento, Paula Carvalho (1990), deu o nome de trajeto antropológico que, segundo o autor, é o produto da articulação entre o bio-psíquico e o sociocultural, o subjetivo e o objetivo, que permite aos humanos realizar a sutura epistemológica entre a Natureza e a Cultura, mediada pelo símbolo e, ao mesmo tempo, construir seus aparelhos simbólicos.

Apropriando-me dessas reflexões sobre meu processo de corporificação, de constituição do ser, com destaque para a inserção na docência e atuação ao longo de quase quatro décadas, opto neste artigo por apresentar algumas reflexões sobre o legado de Paulo Freire para uma compreensão sobre a corporeidade e o lazer. Para tanto, a referência será o trajeto antropológico por mim trilhado e as muitas histórias, que eu e, certamente, tantos(as) outros(as) professores(as) da minha geração, têm para contar. Com esse intuito, lançarei mão de narrativas, apoiada em Chaves (2014), para quem esta tem como função "fazer nossas ações inteligíveis para nós e para os outros" (CHAVES, 2014, p. 88). Ao desenvolver narrativas auto(mito)poiéticas, exploro registros de minha vida e memória em consonância com o que diz a autora:

Os professores podem usar histórias de suas experiências profissionais para refletir sobre a sua própria prática, para articular valores e crenças, para dar 
forma à teoria de ensino e para melhor entendimento do processo decisório - as histórias interagem com os leitores, com os ouvintes e com outros contadores de histórias. Essas histórias são frequentemente base para reflexão, discussão e debate. (CHAVES, 2014, p. 89)

\section{Os encontros com Paulo Freire}

Iniciei a graduação em Educação Física na Universidade Federal de Minas Gerais (UFMG) em 1980, ainda na ditadura militar. O ensino tecnicista imperava em nossa sociedade, fruto de uma legislação (LDB 5692/71) que previa a construção de um projeto nacionalista de ordem e progresso em que a preparação dos(as) jovens para o trabalho era uma premissa. Nesse contexto, se ampliava também a preocupação com as atividades que o trabalhador realizaria no seu tempo livre. Nosso curso, obviamente, coadunava com esse projeto e, por meio das disciplinas ministradas, preparava o futuro licenciado para tratar o(s) corpo(s) de educandos(as) com vistas a uma formação da técnica, do caráter, da disciplina e da obediência. Para tanto, nessa referida legislação, apenas à disciplina Educação Física eram dedicadas determinações por meio de um Decreto - o 69450/71.

Esse Decreto previa como finalidade da disciplina o desenvolvimento da aptidão física, uma vez que ao sistema interessava os indivíduos saudáveis, aptos e capazes para atenderam as demandas do trabalho e da técnica, visto que, por meio dos esportes, era possível desenvolver as ideias de disciplina, automação, eficiência e eficácia para a obtenção de resultados positivos na produção e a consequente conquista da vitória. Nos dizeres de Vaz (2003), a técnica alcançada por meio do esporte se alia a uma verdadeira "adaptação clandestina ao maquinário e à logica do trabalho" (p.66).

Nossa formação inicial nesses tempos se dava de modo diferenciado em relação aos sexos, existindo em vigor dois cursos: um para as mulheres, outro para os homens, com disciplinas distintas em ambos. O currículo privilegiava as disciplinas de cunho biológico e as práticas dos diversos conteúdos corporais (com ênfase nas técnicas e táticas), desprovidas de uma reflexão crítica em ambos os casos. Os conhecimentos relativos à formação docente ocorriam na Faculdade de Educação, onde interagíamos com outras licenciaturas. Em várias disciplinas nos foi 
proporcionado o encontro com os escritos de Paulo Freire. Lembro-me da disciplina "Prática de Ensino da Educação Física", a única específica do nosso curso que despertou nos futuros professores(as) o pensamento crítico e permitiu refletir sobre a função social da disciplina na escola, instigando-nos a questionar: será que "a Educação Física cuida do corpo e mente?”. (MEDINA, 1983)

Ainda que a formação universitária me direcionasse para uma leitura de mundo alienada, vivíamos, naquele momento, uma sociedade que se conscientizava dos efeitos nefastos da ditadura e uma efervescente luta pela redemocratização do país estava em curso, com a criação de partidos de esquerda e vários movimentos sociais organizados. Nessa esteira, logo no início da graduação estive com tantos(as) outros(as) colegas na chapa que assumiu o Diretório Acadêmico do nosso curso, num processo gradual de inserção nas questões políticas que permeavam o contexto da época. Do mesmo modo, nos inserimos no movimento estudantil ampliado, participando dos primeiros Encontros Nacionais de Estudantes de Educação Física cuja edição de número trigésima nona ocorreu em 2019, na cidade de Goiânia (GO). Outra formação paralela se deu num projeto de formação de professores(as) de Educação Física ${ }^{1}$ coordenado pela UFMG e realizado nas escolas da periferia de Belo Horizonte. Esse projeto contribuiu sobremaneira para que eu definisse minha opção por ser professora. Relembro com carinho dos ricos momentos de trocas e reflexões entre os coordenadores e estagiários, ao articular a teoria com a prática, ampliar o olhar sobre a realidade educacional bem como sobre os sujeitos.

Mais ao final da graduação, iniciei minha carreira docente na rede estadual, na condição de professora contratada, infelizmente, uma realidade que ainda se faz presente até os dias de hoje, uma vez que os concursos são escassos. Nessa condição, minha visão de mundo, da sociedade capitalista, da luta dos(as) trabalhadores(as), principalmente em educação, do papel da docência, se ampliou. Pude participar dos movimentos sindicais, de infinitas reivindicações por melhores condições de trabalho, contra os arrochos salariais sofridos e pela valorização da profissão docente. A luta pela redemocratização do país foi um momento fértil de reflexões e

\footnotetext{
${ }^{1}$ Projeto de Criação e Implantação de Laboratórios de Educação Física nas Quatro Primeiras Séries do $1^{\circ}$ grau e Pré-Escolar da Rede Estadual de Minas Gerais. Secretaria de Estado da Educação de Minas Gerais. Belo Horizonte, 1984.
} 
de mudanças. Nos incontáveis movimentos de greve discutíamos o papel da educação no contexto da ditadura, a função social da escola e o compromisso docente.

Paulo Freire estava lá, despertando nossa consciência crítica, instigando a reflexão sobre o poder, a resistência, dialogando com Bourdieu e Passeron (1992), e discutindo a ideia da educação como reprodutora do sistema capitalista, e da escola como aparelho ideológico do estado, com Althusser (1970) dentre tantos outros autores. Paulo Freire estava lá, nos provocando a repensar a educação disciplinar, propedêutica, eurocêntrica, elitista, opressora, bancária; nos convocando a assumir o dever de lutar pela educação como direito de todos(as), em sua perspectiva transformadora e libertária. Naquele momento Freire já nos chamava a atenção de que "o que não é possível é simplesmente fazer o discurso democrático, antidiscriminatório e ter uma prática colonial”. (FREIRE, 1993, p. 68)

Em 1992, já como professora efetiva, atuei na coordenação da Educação Física na Delegacia de Ensino da Rede Estadual ${ }^{2}$ e, nessa condição, tive a oportunidade de participar do "Seminário sobre o pensamento de Paulo Freire", ocorrido na cidade de Poços de Caldas. Foi emocionante ouvir o próprio Paulo Freire, Moacir Gadotti, Ana Maria Saul e tantas outras referências.

Figura 1: Seminário sobre o Pensamento Paulo Freire, 1992

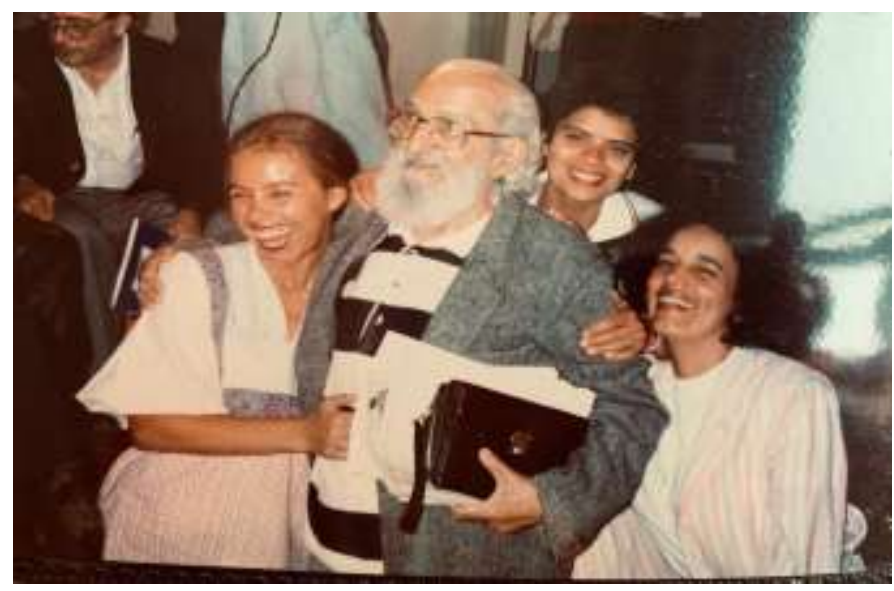

Fonte: autor desconhecido

${ }^{2}$ Unidades administrativas atreladas às Secretarias de Educação do país, criadas na década de 1970, momento em que se valorizavam as estruturas centralizadas e burocráticas. (MENEZES, 2001) 
Esse seminário foi um divisor de águas em minha vida. Voltei convicta que gostaria de atuar no ensino superior. Iniciei, naquele momento, minha caminhada realizando uma especialização em Educação Física Escolar (PUC Minas) e, ao mesmo tempo, em Lazer (UFMG/SESI).

Nesses tempos, idos da década de 1990, fui professora da Escola Municipal Tabajara Pedroso e estávamos no momento de implantação do Programa Escola Plural. Essa era uma proposta inovadora que pretendia valorizar experiências diferenciadas que já vinham ocorrendo na Rede Municipal de Belo Horizonte (RMBH) em relação às práticas pedagógicas, introduzindo importantes reflexões em todo o sistema educacional municipal. Desse modo, a RMBH, inserida num contexto nacional mais amplo (Escola Candanga em Brasília, Escola Cidadã em Porto Alegre), assumia o compromisso das instituições escolares com a educação pública, gratuita e de qualidade (BAPTISTA, 1998), e Paulo Freire era a maior inspiração das mudanças. $\mathrm{O}$ direito à educação foi o mote principal para implementação dessa proposta. Para isso, segundo Baptista (1998), não bastava universalizar o acesso dos sujeitos a escola, mas também adotar mecanismos de publicização das vagas com vistas a garantir a inclusão de crianças e adolescentes em regime de proteção tutelar. Em ação conjunta com os Conselhos Tutelares previa o atendimento às famílias desses educandos, de modo que essas reconhecessem o valor social da escola numa dimensão emancipatória.

Também na internalidade das escolas, o Programa propunha importantes mudanças. A formulação da proposta pedagógica ficava a cargo da comunidade escolar, que definia as ações referentes ao seu cotidiano; as necessidades dos envolvidos no processo; a organização dos tempos e espaços; a construção do conhecimento de modo interdisciplinar, alterando as matrizes curriculares; o reconhecimento da expressão da cultura identitária dos grupos sociais; os métodos avaliativos, dentre tantas outras. Para a implantação dos projetos políticopedagógicos (PPPs) nas escolas, a gestão democrática, exercida pela direção e coordenações de turno, era realizada pelos próprios professores(as) que constituíam as chapas, sendo o pleito definido pelos votos de toda a comunidade escolar. 
No "Tabajara" vivemos experiências singulares. Destaco aqui uma delas, marcante pelo seu caráter democrático, emancipatório, ousado e coletivo. Para a definição de todas as conduções do processo educativo realizávamos um Congresso Político-Pedagógico (CPP's) no qual toda a comunidade acadêmica tinha voz e poder de decisão. Sua periodicidade era bianual, sendo realizado entre os anos de 1991 e 2008.

Figura 2: Capas de algumas pastas com materiais disponibilizados aos participantes dos CPP's da Escola Municipal Tabajara Pedroso
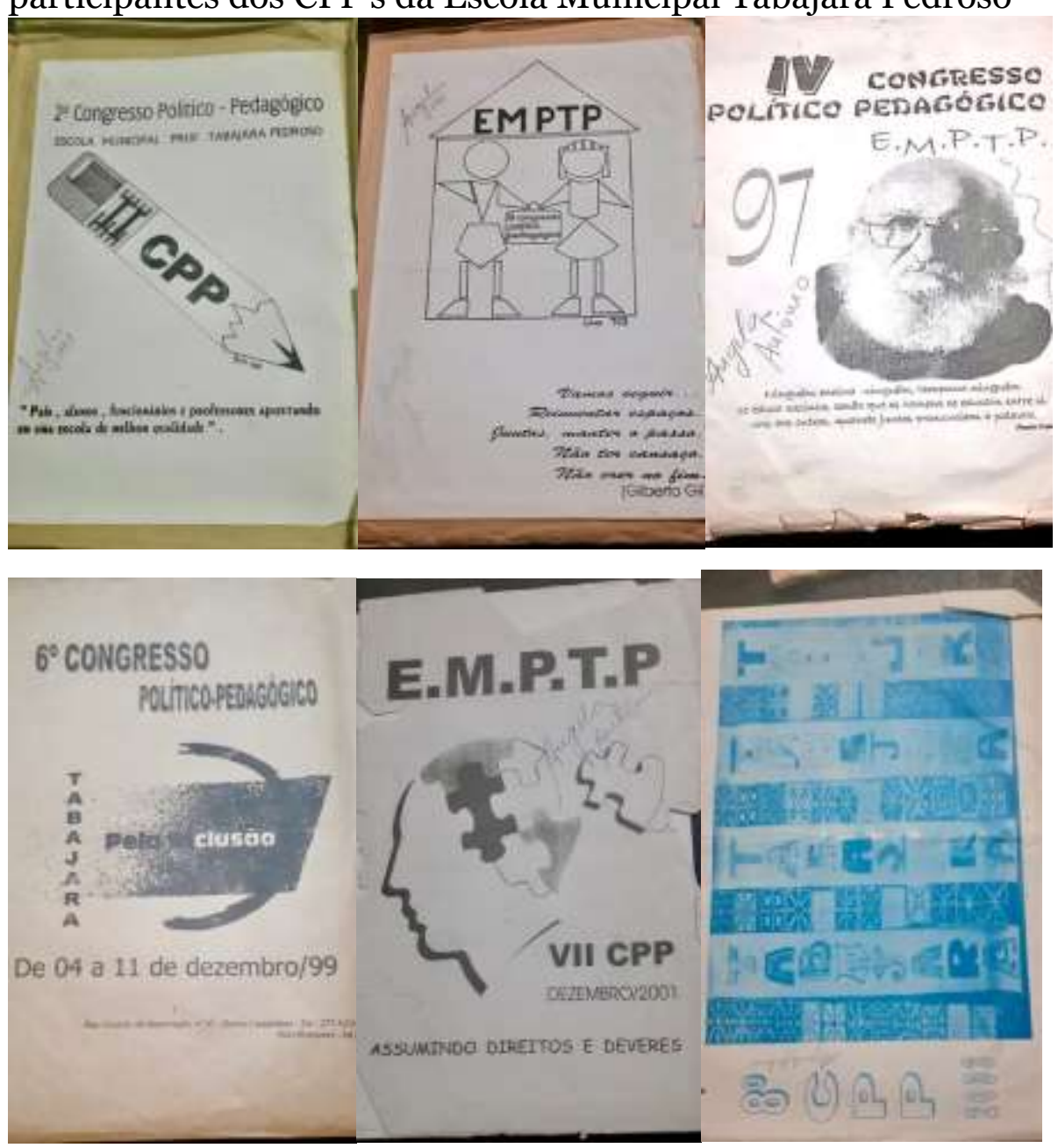

Fonte: Acervo pessoal da Professora Maria Ângela Antônio

Nesses CPP's eram definidas demandas do corpo discente, como o uso obrigatório (ou não) do uniforme escolar ou se o portão da escola permaneceria aberto ao longo de todo o período do turno, do corpo docente, como avaliações, e de cunho mais administrativo-pedagógico, como a organização das disciplinas, a gestão 
da merenda, entre outras. Participavam do Congresso toda a comunidade escolar: pais/mães e responsáveis de alunos(as); estudantes de todas as séries e turnos, funcionários(as), professores(as), direção e, ainda, representantes dos movimentos sociais organizados da região. Adotando os modelos sindicais da época, uma teseguia era escrita para análise, inclusão e exclusão de propostas por todos os representantes.

As discussões eram realizadas em pequenos grupos e no último dia fazíamos uma plenária geral com defesas favoráveis e contrárias às propostas e, em seguida, a definição pelo voto da maioria. Recordo-me de assembleias lotadas, da energia efervescente no plenário, dos nervos alterados para aprovação das propostas, das articulações entre os pares. Mas o que mais me chamava a atenção era o desenvolvimento da criticidade nos alunos que, mesmo com pouca idade, já entendiam o que era viver um processo democrático e dialógico, onde o interesse da maioria prevalecia. Num desses Congressos o patrono foi o próprio Paulo Freire.

Nesse tempo, a Prefeitura de Belo Horizonte, por meio da Secretaria Municipal de Educação (SMED), garantia o pagamento de horas/aulas para a implementação dos PPPs das escolas e, desse modo, era possível implementar as propostas aprovados nos CPPs. Além do pagamento de horas, a Prefeitura também passou a realizar a formação em serviço dos professores(as), criando para isso setores como a Coordenação Político Pedagógica (CPP) e o Centro de Aperfeiçoamento do Professor (CAPE).

Nos últimos anos de minha experiência no "Tabajara" trabalhávamos inspirados pela "pedagogia de projetos" (HERNANDEZ; VENTURA, 1998; dentre outros) e algumas experiências interdisciplinares foram possíveis. Lembro-me da aprovação, no último congresso que participei, da equidade no número de aulas das disciplinas que compunham a matriz curricular. Essa ação revolucionou a escola. Trabalhar a Educação Física em três aulas semanais por turma foi um rompimento com a hierarquia dos saberes escolares. Pela primeira vez, o corpo foi considerado com o mesmo status do intelecto, ao mesmo tempo em que teve reconhecida a sua dimensão cognitiva, presente nas práticas propostas. Vale destacar que, nessa época, a Educação Física passou a ser considerada área do conhecimento que, por meio da 
linguagem corporal, desenvolvia os conhecimentos pertinentes à cultura corporal de movimentos (esportes, ginásticas, danças, lutas, jogos e brincadeiras) como proposto pelo Coletivo de Autores (1992) e assumido na LDBEN de 1996.

O foco no debate sobre a cultura, a diferença, o respeito ao outro, aos corpos me levou ao mestrado desenvolvendo junto a uma comunidade indígena de Minas Gerais, os Maxakali, uma pesquisa sobre os seus jogos e brincadeiras (ALVES, 1998), e, mais à frente, ao doutorado, estudando a festa dos negros de nosso Estado, em homenagem à Nossa Senhora do Rosário (ALVES, 2008). Paulo Freire esteve o tempo todo instigando e desenvolvendo minha "curiosidade epistemológica". Dizia ele:

volto a insistir na necessidade imperiosa que tem o educador e a educadora progressista de se familiarizar com a sintaxe, com a semântica dos grupos populares, de entender como fazem eles sua leitura do mundo, de perceber suas manhas indispensáveis à cultura de resistência que se vai constituindo e sem a qual não podem defender-se da violência a que estão submetidos. (FREIRE, 1992, p. 107).

Especificamente em relação ao congado, me propus a "entender o sentido de suas festas no corpo da cultura de resistência, sentir sua religiosidade de forma respeitosa, numa perspectiva dialética e não apenas como se fosse expressão pura de alienação". (FREIRE, 1992, p. 107)

Em minha prática pedagógica no ensino superior por mais de vinte anos, atuando na formação de turismólogos, professores e professoras, tanto na Educação Física quanto na Pedagogia, e, atualmente, na Pós-Graduação em Educação, me coloco ao lado das pessoas oprimidas, dos(as) trabalhadores(as) e da luta por uma sociedade menos desigual. A educação das sensibilidades tem sido o foco do meu trabalho e o destaque para a reflexão sobre a corporeidade, na busca pelo reconhecimento da sua dimensão amorosa, afetiva, lúdica, imaginante e ética.

\section{Paulo Freire e a corporeidade}

Acredito que tenha sido possível perceber como Paulo Freire e a discussão sobre a corporeidade esteve (e está) presente ao longo do meu processo formativo. Lembro-me muito bem de uma conversa com a Professora Leila Pinto, naquele 
seminário em 1992, quando ela disse que Freire não assumia ter feito um estudo aprofundado sobre o corpo, mas, certamente, esse é um conceito que permeia toda a obra desse autor.

Freire pensa o corpo em sua concretude. Ele questiona a noção de ser humano fragmentada em corpo e mente, reforçada pela educação bancária, reprodutivista, que privilegia o intelecto e desconsidera as emoções e a sensibilidade. Para Freire é inconcebível a separação entre o trabalho intelectual e manual.

Paulo Freire foi um homem do diálogo e da amorosidade. Assim, ao propor uma educação libertadora ele afirmava que essa passa pela tomada de consciência do que é o CORPO. Um corpo que se constitui socialmente por meio das práticas sociais. Corpos mediados pela história, carregados de valores da realidade cultural em que estão inseridos. Corpos que não são da Educação Física e sim, de todos os envolvidos com o processo formador de sujeitos. Corpos que em sua multidisciplinaridade se tornam Corpos Conscientes 3 e se expressam por meio de gestos, palavras e outras diferentes linguagens.

Linguagem que, para o autor, é a expressão do conhecimento produzido pelo ser humano na relação sujeito/objeto e que, como forma de comunicação, é carregada de relações de poder. Diz ele em "Por uma pedagogia da Pergunta" que a linguagem não é só a falada, uma vez que a

\begin{abstract}
de natureza gestual, corporal, é uma linguagem de movimento de olhos, de movimento do coração. A primeira linguagem é a linguagem do corpo e, na medida em que essa linguagem é uma linguagem de perguntas e na medida em que limitamos essas perguntas e não ouvimos ou valorizamos senão o que é oral ou escrito, estamos eliminando grande parte da linguagem humana. Creio ser fundamental que o professor valorize em toda sua dimensão o que constitui a linguagem, ou as linguagens, que são linguagens de perguntas antes de serem linguagens de respostas. (FREIRE; FAUNDEZ, 1985, p. 49)
\end{abstract}

Corpos conscientes que, por meio das linguagens, expressam, não uma consciência ingênua, mas sim, uma consciência crítica, capaz de fazer leituras ampliadas do mundo e de nele intervir. Conceber os corpos conscientes implica em reconhecer os seres humanos enquanto expressões plurais da vida, reconhecer a

\footnotetext{
${ }^{3}$ Gonçalves (2012) faz uma interessante pesquisa sobre como o conceito surgiu e se faz presente em diferentes obras de Paulo Freire. Ver "A noção de corpo(s) consciente(s) na obra de Paulo Freire", disponível em http://www.arquivo.cppnac.org.br/wp-content/uploads/2012/o9/CorpoConsciente.pdf
} 
diversidade dos corpos de homens, mulheres, cisgêneros, transgêneros, transversos, queer, crianças, jovens, idosos, indígenas, negros, brancos, ribeirinhos, portadores de deficiências, gordos, magros, dentre tantos outros.

$\mathrm{Na}$ obra citada, os autores nos relatam sobre a diversidade dos corpos e situações vividas no exílio:

O corpo humano, velho ou moço, gordo ou magro, não importa de que cor, o corpo consciente, que olha as estrelas, é o corpo que escreve, é o corpo que fala, é o corpo que luta, é o corpo que ama, que odeia, é o corpo que sofre, é o corpo que morre, é o corpo que vive! Não foi rara a vez em que pondo minha mão afetivamente no ombro de alguém, tive-a, de repente, no ar, enquanto curvando-se, o corpo tocado recusava o meu. (FREIRE; FAUNDEZ, 1985, p. 28)

Com esse relato, Freire em diálogo estabelecido com Faundez, dizia de sua experiência em outras culturas. Ao exercitar a alteridade ele viu a diferença, reconheceu a tolerância enquanto uma ação política, destacando a sabedoria e a virtude da convivência com o diferente como revolucionária, pois é ela (a diferença) que nos coloca diante do diálogo e da possibilidade de nos enriquecermos enquanto sujeitos.

Assim, Freire nos chama a atenção para o conceito plural de cultura ao afirmar que "as culturas não são melhores nem piores, as expressões culturais não são melhores, nem piores, são diferentes entre elas. (...) A cultura não é, está sendo, e não podemos esquecer o seu caráter de classes”. (FREIRE; FAUNDEZ, 1985, p. 25)

E, para ficar só em mais um conceito que me é caro em Freire, trago a liberdade, conceito central em sua obra. No “Dicionário Paulo Freire”, Jung Mo Sung (2010), teólogo coreano radicado no Brasil, destaca a afirmação de Freire sobre o ser humano se diferenciar dos outros animais pela integração ao contexto, situado cultural e historicamente, com capacidade criativa e crítica, enquanto os outros são seres da acomodação. O ser humano não é algo pronto e luta constantemente contra as forças da dominação e opressão.

Para Freire, a liberdade não é a possibilidade de realizar todos os desejos, no sentido de almejá-la sem qualquer limite. Essa seria uma liberdade despótica, negadora de outras vontades. A liberdade daqueles que se consideram os(as) donos(as) do mundo e, de modo egoísta, só veem a si mesmos. Assim, para Freire, a liberdade não "termina onde começa a liberdade do outro, ela se realiza quando se 
encontra com outras pessoas na luta pela sua liberdade e pela das outras" (apud SUNG, 2010, p. 242). Outro ponto que Freire destaca diz respeito aos nossos desejos, sobre o qual o autor revela que o sonho do oprimido é o de se tornar um opressor, pois esse último considera que a realização desse desejo o conduziria a liberdade. Entendia Freire que, ao contrário, isso o levaria a alienação, aos desejos alheios e opressivos.

A liberdade é, portanto, "uma conquista que se alcança na medida em que se luta pela libertação de si, do outro e do mundo" (SUNG, 2010, p. 243). Liberdade implica em exercitar a nossa autonomia para fazer escolhas e isso exige responsabilidade por aquilo que escolhemos. Não podemos esquecer que em toda escolha existe uma renúncia e esse ato exige responsabilidade conosco, com os(as) outros(as) pessoas, com o planeta. Isso é revolucionário!

\section{Corpos conscientes e o lazer}

Viver o corpo consciente é gozar da liberdade de ser o que se é, no seu tempo histórico, em inteireza consigo mesmo, nas interações com os objetos, com outros seres vivos e humanos. Diz Freire num diálogo estabelecido com Nogueira (1996):

A corporalidade é um tipo de consciência que se baseia numa inteireza consigo mesma. E isso se expressa, ao desenvolver-se, nas interações com os objetos e com outros Seres Humanos. Não apenas consciência de mim mesmo que me sugere a consciência do entorno, mas penso eu, a consciência de inteirar-se do Mundo e com o Mundo que me permite criar noções do "eu consciente". (NOGUEIRA, 1996, p. 19)

A corporalidade é viver nossos corpos plurais com respeito à diversidade e às diferenças, lutando contra qualquer ato de discriminação, como o racismo, o machismo, o fascismo, e tantos determinismos coloniais e estruturais em nossa sociedade. É viver as manhas do corpo que resiste nas múltiplas linguagens da arte, da literatura, da música, da dança, da festa, ou melhor, do lazer. É o corpo que reconhece o seu lugar nesse mundo de opressão, mas não desiste e luta para transformá-lo. 
Nesse contexto, não basta entender o lugar que ocupa o trabalho em nossas vidas, mas, sem dúvida, considerar também o do lazer. Numa sociedade moderna e capitalista como a nossa, o lazer tem sido compreendido como um binômio na relação com o trabalho (GOMES, 2019). Nessa perspectiva, o "tempo livre" para o descanso, na verdade, não é livre, e sim, uma extensão do trabalho. O lazer se torna uma face privilegiada da indústria cultural, que por meio de diferentes veículos oferecem práticas lúdicas que atrofiam a imaginação do trabalhador, promovem a distração e o divertimento fora do trabalho, para que se possa suportá-lo (VAZ, 2006). Desse modo, o sistema, por meio de seus processos educativos, que por vezes envolvem também a escola, reforçam, nesses sujeitos, conceitos presentes nos escritos de Paulo Freire, como o da consciência ingênua, da alienação, da domesticação, da desumanização e da perda da condição do sujeito na sociedade.

Entretanto, o campo do lazer (no sentido bourdiesiano) vem se ampliando em nosso país. Apoiado em teorias críticas, entre elas os estudos culturais, os decoloniais e as teorias da complexidade, vem-se contribuindo para que novas reflexões e construções epistemológicas sejam possíveis e despertem cada vez mais a consciência crítica da sociedade brasileira, em especial dos trabalhadores, em busca de seus "corpos conscientes".

Destaco aqui os estudos de Fernando Mascarenhas (2003), que publicou a obra "O lazer como prática de liberdade, uma proposta educativa para a juventude", inspirado em "A educação como prática de liberdade" (FREIRE, 1967). No estudo de Mascarenhas, o autor considera o lazer como um fenômeno tipicamente moderno, resultante das tensões entre o capital e o trabalho, materializado como um tempo e espaço de vivências lúdicas, de organização da cultura, perpassado por relações de hegemonia (MASCARENHAS, 2003).

Com base nesse entendimento, o autor elabora uma proposta de intervenção de ação comunitária, privilegiando a experiência lúdica e educativa, destinada aos trabalhadores e aos grupos sociais menos favorecidos, como possibilidade desses sujeitos refletirem sobre a própria realidade e transformá-la. O método de intervenção prevê uma ação diagnóstica, a definição de temas geradores, a criação de redes temáticas e os ciclos temáticos, como sugeridos por Freire para a educação, 
para pensar a estrutura das ações comunitárias e o desenvolvimento do lazer em articulação com os interesses do grupo praticante. Assim, pensa o autor, o lazereducação assume sua posição política e pedagógica de compromisso com os grupos sociais oprimidos, mediante a resistência e luta pela sobrevivência cotidiana.

O lazer, ainda que numa perspectiva moderna, vem sendo analisado também em sua dimensão subjetiva e na perspectiva da cultura (GOMES, 2019). Nessas abordagens teóricas, a criticidade, o diálogo, o respeito ao outro, aos corpos diferentes, diversos e suas culturas, a transformação social, a ampliação da leitura de mundo dos trabalhadores, a autonomia e liberdade para fazer as escolhas das experiências lúdicas, ganham destaque.

De minha parte, tenho pensado no lazer como um fenômeno cultural da contemporaneidade presente nas sociedades complexas. Em tempos de ambiguidades e incertezas, o lazer tem sido uma das dimensões da vida humana que vem permitindo aos sujeitos viverem o tempo presente e o que esse nos oferece. A angústia do tempo que passa e da morte que se aproxima (DURAND, 2002), comentada no início desse texto, poucas vezes se fez tão real. A pandemia do Covid 19 nos colocou em suspensão com a vida ao longo desses quase dois anos. Projetos de lazer foram adiados: viagens, idas à shows, cinemas, teatros, bares e até mesmo os encontros com amigos e familiares foram interrompidos. A experiência de muitos(as) se resumiu ao interior de suas próprias casas.

Nesse sentido, a desigualdade social se tornou escancarada para toda a sociedade, afinal o número dos que não têm casa nem o que comer aumentou assustadoramente nesses últimos anos, com a presença de um (des)governo fascista que nega a ciência, desconsidera a educação e a cultura, governa apenas em prol de seus interesses e de uma determinada classe social. Definitivamente não estamos no mesmo barco, e sim, na mesma tempestade. A doença não é democrática, uma vez que classes sociais diferentes convivem com realidades também diferentes para o tratamento e a (possível) cura.

É inegável que, nesse contexto, para aqueles que privilegiadamente podem usufruir de diferentes lazeres, esse tem se tornado uma possibilidade de manter a saúde mental e a vida, e, ao mesmo tempo, um instrumento de alienação, se não 
conseguimos analisar criticamente nossas ações e nos deixamos ser seduzidos pelos apelos da indústria cultural, principalmente das tecnologias e redes sociais.

Cada vez mais percebemos que trabalho e lazer não são duas categorias distintas, pelo contrário, elas são antagônicas, dialógicas e complementares (MORIN, 2002). Pensar no fenômeno lazer implica entender as mudanças ocorridas no trabalho, com a diminuição de oferta de vagas, arrochos salariais, aumento do informal, da uberização de algumas profissões e, também, no desemprego. Os desafios, portanto, são muitos.

Paulo Freire nos inspira a pensar que somos sujeitos da nossa história e compreendê-la já é um primeiro passo para nossa ação de resistência libertadora. $\mathrm{O}$ segundo passo, certamente, passa pela compreensão de que os processos educativos que não se dão apenas na escola, mas em todo tempo e espaço nos quais se desenvolvem práticas sociais por meio de relações humanas e seus corpos, entre elas, aquelas construídas no lazer.

Para Paula Carvalho (1990), as práticas sociais são sempre simbólicas e se constituem como manifestações de um universo imaginário intermediado por um sistema sociocultural e suas instituições. A função das práticas simbólicas é organizar a socialidade dos grupos, promovendo vínculos afetivos, de contatos e de solidariedades entre si e com outros. Por esse motivo o autor considera que toda prática social e simbólica é necessariamente educativa (PAULA CARVALHO, 1990, p.27).

Dialogando com esse autor, considero que o lazer, em suas concepções subjetivas e como dimensão da cultura, se torna tempo e espaço privilegiado para a vivência dessas práticas educativas, permeadas pelo simbólico. De leste a oeste, de norte a sul do nosso país, encontraremos práticas simbólicas e educativas no lazer como um campo aberto às novas pesquisas que possam contribuir no entendimento de quem somos nós, sujeitos individuais e coletivos.

Entretanto, para analisar essas práticas uma outra proposição metodológica será necessária. A lógica moderna precisará ser repensada e a conciliação da imagem e do símbolo com a razão, imprescindível. Nesse sentido, a relação da educação com o lazer é potente. A educação escolar cartesiana necessita ampliar o diálogo com as 
experiências humanas sensíveis, muitas delas vividas no tempo do lazer, com vistas a construir novos paradigmas. A razão precisa dar lugar à emoção, a mente ao corpo. É mister romper com os dualismos.

Concordo com Morin (2019), quando esse afirma que o papel da educação é o de contribuir para que os(as) alunos(as) possam enfrentar os problemas da vida. Para ele, a escola ensina certezas e não incertezas e, ainda, propõe um ensino que atende a realidade do capital e não a uma cultura humanista. Segundo esse autor, a sociedade é um misto de ordem e desordem no qual a ilusão é a perfeição e o mundo que vivemos é imperfeito, mas pode ser melhorado.

Assim, defendo em minhas aulas a necessidade urgente de nos (re)educarmos para vivermos experiências corporais (trans)formadoras de educação e de lazer. Reconheço o potencial desse último fenômeno para a nossa formação autopoiética (no sentido de auto produção criativa) e da nossa coletividade, por meio das práticas simbólicas e educativas. Considero que:

o lazer se torna uma possibilidade para o sujeito vivenciar uma educação que objetive a apropriação de ferramentas potencializadoras para a realização de leituras críticas em relação às estratégias reprodutivistas e alienantes presentes em nossa sociedade. Uma educação das sensibilidades, com vista à sua formação integrada, que alcance a saúde, a qualidade de vida (individual) e da vida (coletiva), a felicidade, em harmonia para viver consigo mesmo, com o outro, a sociedade e o meio ambiente, de modo pleno e lúdico. (NORONHA et al, 2010, p. 36)

Por isso, defendo uma educação das sensibilidades que considere outros conhecimentos e saberes, pouco afeitos nas escolas propedêuticas de nosso país. Uma educação embevecida de alma, de sentido, do olhar, da escuta de si e do outro, em diálogo com as diferenças e respeito à alteridade. Uma educação em que a poesia, a música, a literatura, a arte, a festa, a brincadeira, o lazer, seja provedor de anima, de sonhos, de ludicidades e de imaginários. Uma educação que reconheça nessas diferentes práticas educativas, símbolos e arquétipos que possam constituir nos sujeitos, o corpo mitológico de que nos fala Keleman (2001), aberto aos sonhos, devaneios e fantasias. Estaremos contribuindo, assim, para que as futuras gerações possam enfrentar os antigos problemas que não demos conta de resolver, construindo soluções outras. Aqui, mais uma vez a esperança de que tanto nos fala Freire se torna imprescindível. 


\section{Considerações finais}

Finalizo dizendo que Freire permitiu que eu construísse uma concepção de sociedade, de educação, de homens e mulheres; uma visão de mundo, ao lado dos trabalhadores, dos oprimidos, daqueles e daquelas que lutam por justiça social e por um planeta mais humanizado para todos, todas e todes. Sobre esse aspecto vale lembrar que em "Pedagogia da Esperança: um reencontro com a Pedagogia do Oprimido", Paulo Freire nos conta como fez uma autocrítica na escrita de "Pedagogia do Oprimido" e também em "Educação como prática de liberdade", ao concordar com críticas feitas por mulheres, que, por meio de cartas, questionavam sua linguagem machista ao considerar apenas os homens. Segundo ele, este não é um problema menor em sua obra, pois

a discriminação da mulher, expressada e feita pelo discurso machista e encarnada em práticas concretas é uma forma colonial de tratá-la, incompatível, portanto, com qualquer posição progressista, de mulher ou de homem, pouco importa. A recusa a ideologia machista implica necessariamente a recriação da linguagem, faz parte do sonho possível em favor da mudança do mundo. (FREIRE, 1992, p. 68)

Desejo que Paulo Freire permaneça vivo em nossos corações, em nossas práticas sociais e educativas. Ele que tanto denunciou a realidade mundial também nos trouxe muitos anúncios e nos chamou a atenção para os sonhos. Freire nos convida a entender que o sonho também é político e que "o(a) intelectual" tem um papel preponderante em relação ao que se sonha. Diz ele que devemos sonhar o que é possível de ser realizado e que este persiga as condições concretas,

afinal, não se realiza o sonho a partir dele, em si, mas do concreto em que se está. Para isso, é preciso compreender o presente não apenas como presente de limitações, mas também de possibilidade. É preciso, pois, compreender o sonho como possível e como precisando de ser viabilizado e não como algo pré-dado. (FREIRE, 1985, p. 67)

Estamos vivendo tempos de retrocessos, de perda de direitos, perda da dignidade, da volta da fome e da miséria em nosso país. Paulo Freire nunca esteve tão atual, apesar dos esforços de uma parcela retrógada querer apagá-lo de nossas memórias. Mas as sementes da justiça social foram há muito lançadas por nosso 
"Patrono da Educação" e, ao viver nossos CORPOS CONSCIENTES e LÚDICOS renovamos as esperanças no sonho por um mundo melhor e a certeza que tudo isso vai passar. Esperancemos!

Renovemos nossos sonhos possíveis!!!!! Sejamos mais do que homo sapiens, faber, simbolicus, ludicus, demens, assumindo nosso homo amans (MATURANA, 2009), e exercitando o melhor de nossa humanidade: o AMOR. Lembremos que, para Freire, a amorosidade "se materializa no afeto como compromisso com o outro, que se faz engravidado da solidariedade e da humildade”. (FERNANDES, 2010, p. 27)

\section{Referências}

ALTHUSSER, Louis. Ideologia e aparelhos ideológicos do Estado. Lisboa: Presença, 1970.

ALVES, Vânia F. Noronha. O corpo lúdico Maxakali. Desvelando os segredos de um programa de índio. Belo Horizonte, 1999. 178 f. Dissertação (Mestrado em Educação) -: Faculdade de Educação, Universidade Federal de Minas Gerais.

ALVES, Vânia F. Noronha. Os festejos do Reinado de Nossa Senhora do Rosário em Belo Horizonte/MG: práticas simbólicas e educativas. São Paulo, 2008. 251 f. Tese (Doutorado em Educação). Faculdade de Educação Universidade de São Paulo.

BAPTISTA, Mônica Correia. Escola Plural: direito a ter direitos. Cadernos de Formação da Escola Plural. Belo Horizonte: SMED, 1998.

BOURDIEU, Pierre; PASSERON, Jean-Claude. A Reprodução: Elementos para uma Teoria do Sistema de Ensino. 3 ed. Rio de Janeiro: Francisco Alves, 1992.

CHAVES, Iduina Mont'Alverne Braun. Histórias de vida e formação: cultura, imagens e simbolismos. Revista Cadernos de Educação. Pelotas, n. 48, maio/ago., 87-107, 2014 . Disponível em file:///Users/vanianoronha/Downloads/4757-13471-1-PB\%20(1).pdf. Acesso em: 21 set. 2021.

COLETIVO DE AUTORES. Metodologia do Ensino de Educação Física. São Paulo: Cortez, 1992.

DURAND, Gilbert. As estruturas antropológicas do imaginário. 3 ed. São Paulo: Martins Fontes, 2002.

FERNANDES, Cleoni. Verbete Amorosidade. In: STRECK, Danilo R.; REDIN, Euclides; ZITKOSKI, Jaime José. (Orgs.). - Dicionário Paulo Freire. 2 ed. Belo Horizonte. Autêntica Editora, 2010. p. 37-39. 
FREIRE, Paulo. Educação como prática da liberdade. 5 ed. Rio de Janeiro, Paz Terra, 1967.

FREIRE, Paulo; FAUNDEZ, Antonio. Por uma pedagogia da pergunta. 3 ed. Rio de Janeiro: Paz e Terra, 1985.

FREIRE, Paulo. Pedagogia da Esperança: um reencontro com a Pedagogia do Oprimido. 2 ed. Rio de Janeiro, Paz e Terra, 1992.

GOMES, Christianne Luce. Lazer e produção do conhecimento. Belo Horizonte/Rio de Janeiro: UFMG/SESC-DN, 2019.

GONÇALVES, Luiz Gonzaga. A noção de corpo(s) consciente(s) na obra de Paulo Freire. $\quad 2012$ Disponível em http://arquivo.cppnac.org.br/wpcontent/uploads/2012/og/Corpo-Consciente.pdf Acesso em 20 set. 2021.

HERNÁNDEZ, Fernando; VENTURA, Montserrat. A organização do currículo por projetos de trabalho. O conhecimento é um caleidoscópio. Porto Alegre: Artmed, 1998.

HILLMAN, James. O mito da análise. Três ensaios de psicologia arquetípica. Rio de Janeiro: Paz e Terra, 1984.

KELEMAN, Stanley. Mito e corpo. São Paulo: Summus Editora, 2001.

JUNG, Carl Gustav, VON FRANZ, Marie Louise, HENDERSON, Joseph L.; JAFFE, Aniela. O homem e seus símbolos. Rio de Janeiro: Nova Fronteira, 2002.

MASCARENHAS, Fernando. Lazer como prática da liberdade. Uma proposta educativa para a juventude. Goiânia: Editora UFG, 2003.

MATURANA, Humberto. Emoções e linguagem na educação e na política. Belo Horizonte: Editora UFMG, 2009.

MEDINA, João Paulo Subirá. A Educação Física cuida do corpo e mente. Campinas: Papirus, 1983.

MENEZES, Ebenezer Takuno de. Verbete Delegacias de Ensino. Dicionário Interativo da Educação Brasileira - EducaBrasil. São Paulo: Midiamix Editora, 2001. Disponível em https://www.educabrasil.com.br/delegacias-deensino. Acesso em: 29 set. 2021.

MERLEAU-PONTY, Maurice. Fenomenologia da percepção. 2 ed. São Paulo: Martins Fontes, 1999.

MORIN, Edgar. O método IV. As ideias. 3 ed. Porto Alegre, RS: Editora Sulina, 2002.

MORIN, Edgar. O papel da educação em tempos de crise. Revista Prosa Verso e Arte. O Globo. Entrevista cedida a Audrey Furlaneto, 2019. Disponível em https://www.revistaprosaversoearte.com/resistir-as-incertezas-e-parte-daeducacao-diz-edgar-morin. Acesso em 28 set. 21.

NOGUEIRA, Adriano (Org.). Reencontrar o corpo: ciência, arte, educação e sociedade. Taubaté: Cabral Geic, 1996. 
NORONHA, Vânia et al. Sistema de Monitoramento Avaliação dos Programas Esporte e Lazer da Cidade e Segundo Tempo do Ministério do Esporte. Belo Horizonte: O Lutador, 2010.

PAULA CARVALHO, José Carlos. Antropologia das organizações e educação. Um ensaio holomônico. Rio de Janeiro: Imago Editora, 1990.

SUNG, Jung Mo. Verbete Linguagem. In: STRECK, Danilo R.; REDIN, Euclides; ZITKOSKI, Jaime José. (Orgs.). - 2 ed. Dicionário Paulo Freire. Belo Horizonte. Autêntica Editora, 2010. p. 241-243.

VAZ, Alexandre Fernandes. Reflexões de passagem sobre o lazer: notas sobre a pedagogia da indústria cultural. Revista Pensar a Prática, Belo Horizonte. v.1, n.9, p. 13-26. jan./jun. 2006. Disponível em https://www.revistas.ufg.br/fef/article/view/122. Acesso em: 20 set. 2021

VAZ, Alexandre Fernandes. Corpo, educação e indústria cultural na sociedade contemporânea: notas para reflexão. Revista Pro-Posições, v. 14, n. 2(41), p. 6175, maio/ago. 2003. Disponível em:

https://periodicos.sbu.unicamp.br/ojs/index.php/proposic/article/view/8643886 $\not 11356$.

Acesso em: 20 set. 2021

\section{Sobre a autora}

Vania de Fatima Noronha Alves: Graduada em Educação Física. Especialista em Lazer e em Educação Física Escolar. Mestre e Doutora em Educação. Professora do Programa de Pós-Graduação em Educação e das graduações em Pedagogia e Educação Física da PUC Minas. Autora dos livros "Rastros de África no Brasil: práticas educativas no Reinado de Nossa Senhora do Rosário" e "O corpo lúdico Maxakali: segredos de um programa de índio" E-mail: vaninhanoronha@gmail.com ORCID: orcid.org/oooo-0003-3075-4906

\section{Tramitação:}

Recebido em:29/o9/2021

Aprovado em:04/11/2021 